\title{
ON THE DEFINITION OF "FOREIGN ELEMENT" IN PRIVATE INTERNATIONAL LAW AND THE SIMPLICITY OF UNDERSTANDING THE LAW
}

\author{
Igor B. Ilovaisky \\ Volgograd State University, Volgograd, Russian Federation
}

Introduction: the domestic theory of state and law is based on the use of certain basic legal categories, which as a foundation connect all legal science and make it complete and logically linked. All the branches of domestic law are arranged in the same way, including private international law, and the fundamental definition here is the concept of "foreign element". Despite the sufficient period of its existence and use, this category is a stable subject of scientific disputes, and in practice there are often ambiguous situations associated with its application. In this connection, the purpose of this paper is to study the prospects of normative improvement of the domestic norms of private international law in terms of the definition of foreign element.

Methods: the research is based on the application of logical, dialectical techniques and methods of scientific knowledge, comparative law and legal-technical analysis of texts of the normative acts and materials of the law enforcement practice.

As a result of the study the analysis of the evolution of the category "foreign element" in the domestic private international law, its relationship with the subject of this branch of law, the importance for the implementation of practical and teaching activities, as well as the critical views on this term in the Russian legal science. This approach, including the study of the domestic and foreign legislation became the basis for the conclusion that the Russian legislator is not accurate enough in determining the content of the concept of "foreign element". The developments of legal science and positive foreign experience are poorly used in this area. Meanwhile, a more thoughtful approach in this area would contribute to the creation of unified legal concepts in the law of different states, and clear understanding of the language used in the law within the legal system of each state separately, and the exclusion of abuse from the law enforcement, and as a result, to greater investment attractiveness of the economy of this country.

Key words: private international law, international relations, foreign element, legal fact, object, legal relationship.

Citation. Ilovaisky I.B. On the Definition of "Foreign Element" in Private International Law and the Simplicity of Understanding the Law. Legal Concept, 2019, vol. 18, no. 2, pp. 99-106. (in Russian). DOI: https://doi.org/ 10.15688/lc.jvolsu.2019.2.16

УДК 347.41

ББК 67.404 .2
Дата поступления статьи: 01.03.2019

Дата принятия статьи: 20.03.2019

\section{О ДЕФИНИЦИИ «ИНОСТРАННЫЙ ЭЛЕМЕНТ» В МЕЖДУНАРОДНОМ ЧАСТНОМ ПРАВЕ И ПРОСТОТЕ ПОНИМАНИЯ ПРАВА}

\author{
Игорь Борисович Иловайский \\ Волгоградский государственный университет, г. Волгоград, Российская Федерация
}

Введение: отечественная теория права построена на использовании определенных базовых правовых категорий, которые как фундамент связывают всю юридическую науку и делают ее полной и логически связанной. Также устроены все отрасли отечественного права, в том числе и международное частное право, 
а основополагающей дефиницией здесь выступает понятие «иностранный элемент». Несмотря на достаточно долгий период своего существования и использования эта категория является устойчивым предметом научных споров, а на практике часто встречаются неоднозначные ситуации, связанные с ее применением. В связи с чем целью настоящей публикации является рассмотрение перспектив нормативного совершенствования отечественных норм международного частного права в части определения дефиниции «иностранный элемент».

Методы: изыскание основано на применении логического, диалектического приемов и способов научного познания, сравнительно-правового и юридико-технического анализа текстов нормативных актов и материалов правоприменительной практики.

В результате исследования был проведен анализ эволюции категории «иностранный элемент» в отечественном международном частном праве, взаимосвязь его с предметом этой отрасли права, значимость для осуществления практической и преподавательской деятельности, а также критические взгляды на этот термин в российской правовой науке. Такой подход, а также рассмотрение отечественного и зарубежного законодательства стали основой для вывода, что российский законодатель не достаточно точен при определении содержания понятия «иностранный элемент». Слабо используются разработки правовой науки и позитивный зарубежный опыт в этой сфере. Между тем более вдумчивый подход в исследуемой области способствовал бы и созданию унифицированных юридических понятий в праве разных государств, и ясному пониманию используемых в законе формулировок внутри правовой системы каждого государства отдельно, и исключению из правоприменительной практики злоупотреблений, а в итоге большей инвестиционной привлекательности экономики нашего отечества.

Ключевые слова: международное частное право, международные отношения, иностранный элемент, юридический факт, объект, субъектный состав правоотношения.

Цитирование. Иловайский И. Б. О дефиниции «иностранный элемент» в международном частном праве и простоте понимания права // Legal Concept = Правовая парадигма. -2019. - Т. 18, № 2. - C. 99-106. DOI: https://doi.org/10.15688/lc.jvolsu.2019.2.16

\section{Введение}

В процессе создания общих норм права между государствами, основой которых являются международные конвенции, соглашения и договоры, возрастает необходимость формирования общих для стран мира правовых понятий и создание, таким образом, совместной, то есть унифицированной правовой базы [18, c. 241]. Не менее важно, на наш взгляд, совершенствовать понимание и юридическую точность закрепления в законе подобных категорий внутри правовой системы каждого государства отдельно. Таковой, то есть интернациональной, с одной стороны, а с другой - требующей усовершенствования в отечественном законодательстве, на наш взгляд, является дефиниция «иностранный элемент».

\section{Определение и значимость категории «иностранный элемент» в международном частном праве}

Термин «иностранный элемент» используется при характеристике предмета международного частного права, который включает в себя как минимум четыре группы общественных отношений: международные, гражданские, семейно-брачные и трудовые [4, с. 18]. При этом возникает необходимость объяснить, в каком случае общественные отношения становятся международными. То есть ответить на вопрос: «Какие квалифицирующие признаки придают общественному отношению характер международности?» Ответ имеет важное практическое значение, так как от того, международное оно или внутригосударственное, зависит выбор и нормативных источников для дальнейшей квалификации спора; и принципов и методов, на основе которых будет осуществляться правоприменение, в том числе толкование норм, восполнение пробелов, способов защиты, характер санкций и т. п. Если будет признано, что это международное отношение, то возможно применение норм унифицированных договоров или права иностранного государства, содержание которых может отличаться, а иногда и существенно, от содержания отечественного законодательства. Если же вывод будет в пользу внутригосударственной природы спорного отношения, применяться будут исключительно нормы права конкретного государства. 
И.Б. Иловайский. О дефиниции «иностранный элемент» в международном частном праве

Значимость изложенного хорошо подтверждает пример из нотариальной практики, произошедший в конце 2011 г. в Нотариальной палате Волгоградской области. Семья из города Волгограда - муж и жена, граждане РФ, зарегистрированные по месту жительства в нашем городе, после рождения у них внука в Израиле решили на время приехать в эту страну, что называется - «в гости», и порадоваться рождению внука, а также для оказания помощи родителям этого маленького гражданина. Отъезд из Израиля задержался, и супруги прожили в этой стране более 2 лет, после чего глава этой семьи внезапно ушел из жизни, что подтверждалось местным свидетельством о смерти. Вдова в целях принятия наследства после смерти мужа вернулась в Россию, где у них находилась в совместной собственности квартира и вклад в банке.

При обращении в нотариальную контору г. Волгограда возник вопрос о характере этих отношений, а именно международные они или внутрироссийские? Если признать их международными, то к отношениям по наследованию движимого имущества, в силу п. 1 ст. 1224 ГК РФ, нотариусу будет необходимо применять право Израиля. Если же они признаются внутригосударственными, то наследование будет осуществляться исключительно на основе российского гражданского права (Раздел V Наследственное право ГК РФ). Наверное, нет необходимости объяснять, что найти нормы гражданского и наследственного права Израиля, да еще переведенные на русский язык, в Волгограде является достаточно проблематичным...

Квалификация всех подобных прецедентов в качестве международных или внутрироссийских осуществляется в международном частном праве на основе использования понятия «иностранный элемент». По этому поводу доктор юридических наук, профессор Г.К. Дмитриева указывает, что «частные правоотношения приобретают международный характер, когда в их составе появляется так называемый “иностранный элемент”. Именно иностранный элемент придает им новое сущностное качество, порождая потребность в особых приемах и средствах правовой регламентации. В результате появляется новая понятийная сущ- ность - частноправовые отношения с иностранным элементом» [13, с. 12].

\section{Возникновение и развитие понятия} «иностранный элемент» и его критика в отечественном международном частном праве

Если посмотреть на историю возникновения этого термина, то первыми учеными-правоведами, которые стали его использовать в своих работах, были доктор юридических наук, профессор И.С. Перетерсткий и доктор юридических наук, профессор С.Б. Крылов [9]. Они высказывали мысль, что может сложиться ситуация, когда элементы правоотношения связаны с двумя государствами (цит. по: [16, с. 7]). Однако более широкое употребление рассматриваемой дефиниции было осуществлено профессором Л.А. Лунцем [11, с. 26-27], а затем было подхвачено большинством отечественных исследователей в сфере международного частного права [2; 4; 6-8], а также зарубежных правоведов [3; 19-22].

Традиционно большинство исследователей не дают теоретического определения понятия «иностранный элемент», а формируют его путем перечисления составных частей, которые в него входят. Так, В.А. Канашевский пишет, что «принято выделять три вида иностранного элемента в составе правоотношения, регулируемого нормами международного частного права:

1) субъект отношения - иностранное физическое или юридическое лицо, а в отдельных случаях государство или международная организация. Например, ...договор купли-продажи, заключенный между иностранной фирмой и российской организацией и т. д.;

2) объект отношения - имущество, находящееся за рубежом. Например, наследственное имущество, находящееся за рубежом, в то время как наследодатель и наследники проживают в России;

3) юридический факт, имевший место за границей. Например, причинение вреда российскому лицу имело место за рубежом или за рубежом была совершена сделка, ...был заключен брак, выполнялась работа и т. п...» [8, с. 15].

Такой подход к определению иностранного элемента регулярно подвергается в оте- 
чественной юридической литературе критике. Особенно ярко это проявляется в работах доктора юридических наук, профессора А.А. Рубанова [16; 17]. Суть его аргументов сводится к тому, что при рассмотрении субъектов частного правоотношения любого правоприменителя интересуют их юридически значимые свойства, которые, по сути, сводятся к правосубъектности таких лиц, то есть их правоспособности и дееспособности. Например, вступая в сделки, их участники должны задуматься о таких качествах своих контрагентов, чтобы впоследствии было невозможно признать эту сделку недействительной по причине порока в его субъекте (см. ст. 171176 ГК РФ). В случае же с частноправовыми международными отношениями значимость приобретает гражданство или место жительства физического лица или государственная принадлежность организации. А это, по мнению А.А. Рубанова, не является верным с точки зрения теории права. Подобное замечание касается и объекта, как разновидности иностранного элемента, так как квалифицирующее значение приобретает место его нахождения в иностранном государстве, а не внутренние свойства, позволяющие включить его в гражданский оборот.

Что касается юридического факта, то польский профессор К. Пшибыловский замечал, что «...категория юридического факта, имевшего место за границей... должно здесь по необходимости играть роль резерва, предназначенного охватить все, чего нельзя вместить в другие категории. Но в таком случае пределы понятия "юридического факта, имевшего место за границей”, выйдут за рамки, установленные в науке гражданского права» $[11$, с. 27$]$.

Вместо категории «иностранный элемент» А.А. Рубанов [16; 17, с. 28-33], а позднее и Л.П. Ануфриева предлагают сформировать другой признак, которому должно удовлетворять общественное отношение, подпадающее под действие международного частного права. Таким качеством они предлагают считать «проявление юридической связи данного общественного отношения с правопорядками двух и более государств» [1, с. 61-62]. На этот довод логично появляется вопрос: «А когда проявляется юридическая связь кон- кретного общественного отношения с правопорядками двух и более государств?» Или как объяснить, предположим, студентам при преподавании курса международного частного права, когда такая правовая связь есть, а когда ее нет? Не тогда ли она в наличии, когда в отношениях появляется все тот же «иностранный элемент»?

Оценивая вышеизложенные точки зрения, доктор юридических наук, профессор М.Н. Кузнецов приходит к выводу, что и сторонники теории иностранного элемента, и его критики спорят об одном и том же. При квалификации общественного отношения как международного необходимо выяснить его юридическую связь с правопорядками двух или более государств. Сделать это возможно только после выяснения вопроса о том, содержится ли в этом отношении иностранный элемент (в его трех проявлениях - субъекте, объекте или юридическом факте) или его там нет [10, с. 76-77]. Сам Л.А. Лунц по этому поводу говорил, что «...все же указанные три категории охватывают основное, а случаи, не вмещающиеся не в одну из них, относительно редки. Другая альтернатива - вовсе отказаться от указания видов иностранных элементов или, что тоже самое, считать приведенный перечень лишь примерным - кажется еще менее удачной» [11, с. 27].

Л.П. Ануфриева как дополнительный аргумент в пользу подтверждения несостоятельности дефиниции «иностранный элемент» приводит довод о том, что он не обладает качеством «универсальности» и «всеобщности» для целей идентификации объекта регулирования МЧП. В качестве примера она приводит случай, когда физическое лицо на территории какого-либо государства совершает бытовую сделку, последняя, по ее мнению, не будет регулироваться нормами международного частного права, а будет подлежать регулированию с помощью гражданского права данной юрисдикции [1, с. 61].

Не желая принизить авторитет уважаемого правоведа, позволим себе не согласиться с этими аргументами, так как для бытовых сделок в Разделе IV Международное частное право ГК РФ предусмотрена ст. 1212 «Право, подлежащее применению к договору с участием потребителя», в которой к отно- 
шениям с участием такого лица преимущественно применяется право страны его места жительства (lex domicilii). Аналогичные указанной норме правила содержатся в ст. 114 Федерального закона Швейцарии 1987 г. «О международном частном праве» [12, c. 652], § 41 Федерального закона Австрии 1978 г. «О международном частном праве» [12, с. 165], ст. 29 Вводного закона 1896 г. к Германскому Гражданскому уложению [12, с. 280-281] и пр.

Однако на практике возможны ситуации, когда в общественном отношении содержится иностранный элемент, но он может не иметь значения для квалификации его как международного. К таким прецедентам мы бы отнесли обстоятельства описанного выше примера из практики Нотариальной палаты Волгоградской области. В этом прецеденте иностранный элемент в виде юридического факта смерти российского гражданина на территории Израиля явно имеет место, но для квалификации по основаниям ст. 1224 ГК РФ и выбора применимого права значение имеет не факт смерти физического лица на территории иностранного государства, а факт постоянного проживания на территории конкретной страны. В силу абз. 2 п. 17 Постановления Верховного Суда РФ от 29.05.2012 г. № 9 [15] и в абз. 3 п. 6 Методических рекомендаций по оформлению наследственных прав Федеральной нотариальной палаты [14] такие обстоятельства определяются на основе признака регистрации наследодателя в России. Поэтому, на наш взгляд, изложенный случай нельзя признать международным. Следовательно, для его квалификации нет необходимости в применении ст. 1224 ГК РФ и определении компетентного (применимого) права, так как это внутригосударственные отношения, к регулированию которых нотариус должен применить отечественные нормы наследственного права.

\section{Российское и зарубежное}

законодательство

\section{о понятии «иностранный элемент»}

С принятием 30.04.1999 г. Кодекса торгового мореплавания РФ (далее - КТМ РФ), а затем 26.11.2001 г. части третьей Граждан- ского кодекса РФ понятие «иностранный элемент» перешло из теоретической плоскости в правовую, и было закреплено в ст. 414 КТМ РФ и в ст. 1186 ГК РФ. Так, в соответствии с п. 1 ст. 1186 ГК РФ «право, подлежащее применению к гражданско-правовым отношениям с участием иностранных граждан или иностранных юридических лиц либо гражданскоправовым отношениям, осложненным иным иностранным элементом, в том числе в случаях, когда объект гражданских прав находится за границей, определяется на основании международных договоров РФ, Гражданского кодекса РФ, других законов (п. 2 ст. 3 ГК РФ) и обычаев, признаваемых в РФ». Таким образом, как это верно заметил В.А. Канашевский, «категория “отношения, осложненные иностранным элементом”, в условиях современной российской практики носит нормативный характер, так как закреплена в приведенных выше правовых актах» [8, с. 15-16].

Тем не менее при внимательном прочтении перечисленных норм становится ясным, что у законодателя не нашлось места для указания такого вида иностранного элемента, как юридический факт. Вместо него используется формулировка «гражданско-правовые отношения, осложненные иным иностранным элементом». Конечно, для квалифицированного юриста, прошедшего теоретический курс международного частного права, такого рода загадка, а может быть ребус, не вызовут затруднений, тем более что их можно разрешить путем толкования норм Раздела IV ГК РФ, в содержании которых в качестве оснований выбора применимого права используется и юридический факт, как иностранный элемент (см., например, ст. 1224 ГК РФ, в которой в качестве квалифицирующего для поиска применимого права используется юридический факт последнего места жительства наследодателя). Но подобные ситуации с отечественным законодательством требуют не только дополнительных интеллектуальных усилий, но и создают основу для ненужных на практике дискуссий и споров, что неминуемо приводит к потере времени и ошибочной квалификации спорного правоотношения. Именно так и обстояло дело в вышеизложенном примере из нотариальной практики, в обсуждении которого участвовали не только нотариусы Волгог- 
радской области, но и преподаватели местных высших учебных заведений, и специалисты Центра нотариальных исследований при Федеральной нотариальной палате РФ в городе Екатеринбург.

Между тем обращает на себя внимание то, что в других странах законодатель более удачно подошел к определению указанных выше отношений. Таким примером может являться Закон Украины от 23 июня 2005 г. № 2709-IV «О международном частном праве», в преамбуле которого были достаточно умело, на наш взгляд, объединены и точка зрения сторонников, и противников понятия «иностранный элемент». Так, было закреплено, что «настоящий Закон устанавливает порядок урегулирования частноправовых отношений, которые хотя бы посредством одного из своих элементов связаны с одним или несколькими правопорядками, иными, чем украинский правопорядок». Более того, в ст. 1 этого норматива грамотно с точки зрения теории международного частного права перечислены виды иностранного элемента, а именно указано, что «иностранный элемент - это признак, характеризующий частноправовые отношения, которые регулируются настоящим Законом, и проявляются в одной или нескольких из следующих форм:

- хотя бы один участник правоотношений является гражданином Украины, который проживает за пределами Украины, иностранцем, лицом без гражданства или иностранным юридическим лицом;

- объект правоотношений находится на территории иностранного государства;

- юридический факт, который создает, изменяет или прекращает правоотношения, имел либо имеет место на территории иностранного государства...» [5].

\section{Выводы}

Полагаем, что использование позитивного зарубежного опыта в сфере правотворчества было бы полезным и отечественным правоведам, и депутатам Законодательного собрания РФ. Более того, это способствовало бы и созданию унифицированных юридических понятий в праве разных государств, и ясному пониманию используемых в законе формулировок внутри правовой системы каждого государства отдельно, и исключению из правоприменительной практики злоупотреблений, а в итоге большей инвестиционной привлекательности экономики нашего отечества. В контексте изложенного интересна роль Наполеона Бонапарта в создании Гражданского кодекса Франции 1804 г., при принятии которого он как неюрист настаивал, чтобы законы были написаны ясным и понятным языком. Такой подход был настолько удачен, что даже в период своего изгнания на острове Св. Елены этот человек замечал: «Моя действительная слава заключается не в том, что я выиграл 40 сражений. Ватерлоо стерло в памяти все воспоминания обо всех этих победах. Но, несмотря ни на что, не сотрется в памяти, что будет жить вечно, так это мой гражданский кодекс» $[18$, с. 131-132]. Может быть, именно такого отношения не хватает отечественному законодателю при разработке им нормативных актов, в том числе и в области международного частного права?

\section{СПИСОК ЛИТЕРАТУРЫ}

1. Ануфриева, Л. П. Международное частное право : в 3 т. Т. 1 / Л. П. Ануфриева. - М. : БЕК, 2002. $-288 \mathrm{c}$.

2. Баринов, Н. А. Категория «иностранный элемент» - связующее звено гражданского и международного частного права / Н. А. Баринов, А. Б. Карпачева // Свобода. Право. Рынок : материалы Всеpoc. науч. конф. «40 лет Волгоградской цивилистике», 21-22 мая 2007 года. Вып. 5. - Волгоград : ВА МВД России, 2007. - $256 \mathrm{c}$.

3. Бендевский, Т. Международное частное право : учебник / Т. Бендевский ; пер. с македон. С. Б. Клейн ; отв. ред. Е. А. Суханов. - М. : Статут, 2005. $-466 \mathrm{c}$.

4. Богуславский, М. М. Международное частное право : учебник / М. М. Богуславский. - 3-е изд., перераб. и доп. - М. : Юрист, 1998. - 408 с.

5. Закон Украины от 23 июня 2005 г. № 2709-IV «О международном частном праве» (в ред. Кодекса Украины от 18.03.2004 г. № 1618-IV, Законов Украины от 21.01.2010 г. № 1837-VI, 19.05.2011 г. № 3390VI, 22.12.2011 г. № 4212-VI, 16.05.2013 г. № 245-VII, 24.11.2015 г. № 817-VIII, 03.11.2016 г. № 1724-VIII, 12.07.2018 г. № 2508-VIII). - Электрон. дан. - Режим доступа: http://base.spinform.ru/show_doc.fwx?rgn= 16954 (дата обращения: 10.10.2018). - Загл. с экрана. 
6. Звеков, В. П. Международное частное право. Курс лекций / В. П. Звеков. - М. : НОРМА : ИНФРА-М, 1999. - $686 \mathrm{c}$.

7. Иншакова, А. О. Международное частное право : учебник и практикум для академического бакалавриата / А. О. Иншакова. - М. : Юрайт, 2017. $398 \mathrm{c}$.

8. Канашевский, В. А. Международное частное право : учебник / В. А. Канашевский. - М. : Международные отношения, 2016. - 1008 с.

9. Крылов, С. Б. Международное частное право : учебник / С. Б. Крылов, И. С. Перетерский. М. : Юрид. изд-во НКЮ СССР, 1940. - 205 с.

10. Кузнецов, М. Н. Введение в международное частное право: теоретико-правовое исследование : монография / М. Н. Кузнецов. - М. : Изд-во РУДН, 2014. - 288 с.

11. Лунц, Л. А. Курс международного частного права : в 3 т. / Л. А. Лунц. - М. : Спарк, 2002. $1007 \mathrm{c}$.

12. Международное частное право: Иностранное законодательство. - М. : Статут, 2001. - 892 с.

13. Международное частное право : учебник / Л. П. Ануфриева, К. А. Бекяшев, Г. К. Дмитриева [и др.] ; отв. ред. Г. К. Дмитриева. - М. : Проспект, 2003. -688 c.

14. Методические рекомендации по оформлению наследственных прав : утв. решением Федеральной нотариальной палаты от 27-28 февр. 2007 г. [протокол № 02/07 (извлечение)]. - Электрон. текстовые дан. - Режим доступа: www.notariat.ru (дата обращения: 10.10.2018). - Загл. с экрана.

15. Постановление Пленума Верховного Суда РФ от 29.05.2012 № 9 «О судебной практике по делам о наследовании» // Бюллетень Верховного Суда РФ. - 2012. - № 7. - С. 17.

16. Рубанов, А. А. Вопросы теории правоотношения в международном частном праве / А. А. Рубанов // XXVI съезд КПСС и проблемы гражданского и трудового права, гражданского процесса. - М. : Изд-во ИГиП АН СССР, 1982. - 233 с.

17. Рубанов, А. А. Имущественные отношения в международном частном праве / А. А. Рубанов // Правоведение. - 1983. - № 6. - С. 28-33.

18. Цвайгерт, К. Введение в сравнительное правоведение в сфере частного права : в 2 т. Т. І. Основы : пер. с нем. / К. Цвайгерт, Х. Кетц. - М. : Международные отношения, 2000. - 480 с.

19. Чешир, Дж. Международное частное право / Дж. Чешир, П. Норт. - М. : Юридическая литература, 1982. $-496 \mathrm{c}$.

20. Ludwiczak, W. Miedzynarodowe pravo prywatne / W. Ludwiczak. - W., 1967.-155 p.

21. Scott, A. W. Private International Law (Conflict of Laws) / A. W. Scott. $-2^{\text {nd }}$ ed. - P., 1979. $278 \mathrm{p}$.
22. Sedler, R. A. The Conflict of Laws in Ethiopia / R. A. Sedler. - Addis Ababa ; Nairobi, 1965. - 307 p.

\section{REFERENCES}

1. Anufrieva L.P. Private International law. Moscow, BEK Publ., 2002, vol. 1. 288 p. (in Russian).

2. Barinov N.A., Karpacheva A.B. Category "Foreign Element" - a Link Between Civil and Private International Law. Freedom. Right. Market. Proceedings of the All-Russian Scientific Conference "40 Years of Volgograd Civil Law", May 21-22, 2007. Vol. 5. Volgograd, 2007. 256 p. (in Russian).

3. Bendesky T. Private International law: Textbook. Kleyn S.B., Sukhanov E.A., eds. Moscow, Statut Publ., 2005. 466 p. (in Russian).

4. Boguslavsky M.M. Private International law: Textbook. 3rd ed. Moscow, Yurist Publ., 1998. 408 p. (in Russian).

5. The law of Ukraine of 23 June 2005 № 2709-IV "About private international law" (In the wording of the Code of Ukraine of 18.03.2004№ 1618-IV, Law of Ukraine of 21.01.2010 № 1837-VI of 19.05.2011, № 3390-VI, 22.12.2011, № 4212-VI 16.05.2013, № 245-VII, 24.11.2015, № 817-VIII, 03.11.2016, № 1724-VIII, 12.07.2018, № 2508-VIII). Rubase. URL: http://base. spinform.ru/show_doc.fwx?rgn=16954 (accessed 10 October's 2018).

6. Zvekov V.P. International private law. Course of lectures. Moscow, NORMA Publ., INFRA-M Publ., 1999. 686 p. (in Russian).

7. Inshakova A.O. Private International Law: Tutorial and Workshop for Undergraduate Academic. Moscow, Yurayt Publ., 2017. 398 p. (in Russian).

8. Kanashevsky V.A. Private International Law: Textbook. Moscow, Mezhdunarodnyye otnosheniya Publ., 2016. 1008 p. (in Russian).

9. Krylov S.B., Peretersky I.S. Private International Law: Textbook. Moscow, Jridicheskoe izdatelstvo NKU USSA, 1940. 205 p. (in Russian).

10. Kuznetsov M.N. Introduction to Private International Law: Theoretical and Legal Research: Monograph. Moscow, RUDN Publ., 2014. 288 p. (in Russian).

11. Lunc L.A. Course of International Private Law: in 3 t. Moscow, Spark Publ., 2002. 1007 p. (in Russian).

12. Private International Law: Foreign Law. Moscow, Statut Publ., 2001. 892 p. (in Russian).

13. Anufrieva L.P., Bekyashev K.A., Dmitrieva G.K., eds. Private International Law: Textbook. Moscow, Prospect Publ., 2003. 688 p. (in Russian).

14. Guidelines for registration of inheritance rights: Approved By the Decision of the Federal Notary Chamber of 27-28 February 2007, prot. № 02/07 


\section{ВОПРОСЫ ЧАСТНОПРАВОВОГО РЕГУЛИРОВАНИЯ}

(extraction). URL: www.notariat.ru (accessed 10 October's 2018).

15. Resolution of the Plenum of the Supreme Court of 29.05.2012 № 9 “On judicial practice in cases of inheritance”. Bulletin of the Supreme Court, 2012, no. 7,p. 17.(in Russian).

16. Rubanov A.A. Questions of the Theory of Legal Relations in Private International Law. XXVI Congress of the CPSU and Problems of Civil and Labor Law, Civil Procedure. Moscow, Izdatelstvo IGiP AN USSA, 1982. 233 p. (in Russian).

17. Rubanov A.A. Property Relations in Private International Law. Jurisprudence, 1983, no. 6, pp. 2833. (in Russian).
18. Tsvaygert K., Ketts Kh. Introduction to Comparative Law in the Field of Private Law. T. I. Basics. Moscow, Mezhdunarodnie otnoshenia Publ., 2000. 480 p. (in Russian).

19. Cheshir Dzh., Nort P. Private International Law. Moscow, Yuridicheskaya literatura Publ., 1982. 496 p. (in Russian).

20. Ludwiczak W. Miedzynarodowe pravo prywatne. W., 1967. $155 \mathrm{p}$.

21. Scott A.W. Private International Law (Conflict of Laws). $2^{\text {nd }}$ ed. P., 1979. 278 p.

22. Sedler R.A. The Conflict of Laws in Ethiopia. Addis Ababa; Nairobi, 1965. 307 p.

\section{Information about the Author}

Igor B. Ilovaisky, Candidate of Sciences (Jurisprudence), Associate Professor, Department of Civil and Private International Law, Volgograd State University, Base Department of the Southern Scientific Center of the Russian Academy of Sciences, Prosp. Universitetsky, 100, 400062 Volgograd, Russian Federation,domino@rambler.ru, https://orcid.org/0000-0002-4210-9413

\section{Информация об авторе}

Игорь Борисович Иловайский, кандидат юридических наук, доцент кафедры гражданского и международного частного права, Волгоградский государственный университет, базовая кафедра ЮНЦ РАН, просп. Университетский, 100, 400062 г. Волгоград, Российская Федерация, domino@rambler.ru, https://orcid.org/0000-0002-4210-9413 